\title{
A GAP FOR ME: ENTREPRENEURS AND ENTRY
}

\author{
Volker Nocke \\ University of Pennsylvania
}

\begin{abstract}
We present a theory of entrepreneurial entry (and exit) decisions. Knowing their own managerial talent, entrepreneurs decide which market to enter, where markets differ in size. We obtain a striking sorting result: Each entrant in a large market is more efficient than any entrepreneur in a smaller market because competition is endogenously more intense in larger markets. This result continues to hold when entrepreneurs can export their output to other markets, thereby incurring a unit transport cost or tariff. The sorting and price competition effects imply that the number of entrants (and hence product variety) may actually be smaller in larger markets. In the stochastic dynamic extension of the model, we show that the churning rate of entrepreneurs is higher in larger markets. (JEL: L11, L13, M13, F12)
\end{abstract}

\section{Introduction}

If I can make it there, I'll make it anywhere It's up to you-New York, New York

—Frank Sinatra, "New York, New York"

This paper presents a simple theory of entrepreneurial entry (and exit) decisions. The two main questions addressed in this paper are the following: First, and most important, what is the relationship between the size of a market and the talent of its entrepreneurs-when entrepreneurs can decide which market to enter? Second, given that entrepreneurs self-select into markets, what is the resulting relationship between the size of a market and the turnover (or "churning") rate of entrepreneurs?

Acknowledgments: Financial support by the National Science Foundation (grant SES-0422778) is gratefully acknowledged. I am indebted to John Sutton for his encouragement. I would also like to thank the editor (Xavier Vives), an anonymous referee, Luís Cabral, Carl Davidson, Gilles Duranton, Lucy White, Stephen Yeaple, and seminar participants at Cornell University, the London School of Economics, the University of Wisconsin at Madison, the 2002 Econometric Society North American Winter Meeting (Atlanta), and the 2002 Econometric Society European Summer Meeting (Venice) for helpful comments.

E-mail address: nocke@econ.upenn.edu

Journal of the European Economic Association September 2006 4(5):929-956

(c) 2006 by the European Economic Association

$$
\text { “zwu004060384" - 2006/7/6 — page } 929 \text { - \#1 }
$$


Our model of entrepreneurship is based on the idea that (potential) entrepreneurs differ in their managerial talent. Moreover, we assume that (young) entrepreneurs are "mobile" in that they can freely choose the market they want to enter. For instance, the entrepreneurs may be chefs or restaurateurs who can decide in which city to open a new restaurant, or innovative firms choosing in which country or state to locate their operations. An alternative interpretation is that instead of deciding which geographical market to enter, entrepreneurs must choose which industry to enter at a given location. This paper fills a gap in the industrial organization literature by tackling the important question of how a population of heterogeneous entrepreneurs will allocate itself across different markets. We find that this allocation will be biased, which has wide-reaching implications both for policy and for empirical work.

In this paper, we investigate the relationship between market size and the talent of entrepreneurs. This analysis bears on the large empirical literature on productivity differences across firms and markets; see Bartelsman and Doms (2000) for a survey. Following Sveikauskas (1975) and Henderson (1986), many empirical studies have confirmed that firms are more productive in larger cities or more densely populated regions. These productivity differences have typically been interpreted as evidence for agglomeration externalities. Our theory suggests that such agglomeration economies may be less important than previously thoughtbecause we show that this type of finding could alternatively be explained by our theory, which relies purely on the self-selection of entrepreneurs. In fact, as Marshall (1890) observed in his Principles of Economics:

The large towns and especially London absorb the very best blood from all the rest of England; the most enterprising, the most highly gifted, those with the highest physique and the strongest characters go there to find scope for their abilities.

Hence, productivity in larger towns may be higher not because larger markets make firms more productive but rather because the more capable entrepreneurs enter the larger markets.

Another issue addressed in this paper is the relationship between market size and the turnover rate of entrepreneurs. Again, our analysis is motivated by a large body of empirical literature in industrial organization and labor economics analyzing the pattern of firm entry and exit, and gross job creation and destruction. Several interesting regularities have been identified (see, for instance, Cabral 1997; Caves 1998; and Davis and Haltiwanger 1999). First, cross-industry differences in the rate of firm turnover (or gross job reallocation) are large in magnitude and persistent over time. Second, the ranking of industries by the rate of firm turnover is very similar from one country to another. Third, entry and exit rates are positively correlated across industries; that is, industries with high exit rates are likely to exhibit high entry rates as well. These regularities suggest that certain

$$
\text { “zwu004060384” - 2006/7/6 — page } 930 \text { - \#2 }
$$


industry characteristics (such as the pattern of demand or technology) determine the churning rate. Most previous theoretical models of dynamic industry equilibrium (e.g., Jovanovic 1982; Lambson 1991; Hopenhayn 1992; Ericson and Pakes 1995; and Asplund and Nocke 2006) have assumed that firms are identical when they decide whether or not to enter a market, and so cross-industry predictions result from comparative statics. Following Asplund and Nocke, we examine the effect of market size on churning rates. In contrast to the existing literature, however, we analyze the dynamic industry equilibrium in a model with multiple markets, where heterogeneous entrepreneurs can self-select into markets.

We consider the entry (and exit) decisions of a pool of heterogeneous entrepreneurs. Knowing her own talent, each entrepreneur decides which market to enter, where markets differ only in their size. What is the resulting relationship between the size of a market and the talent of its entrepreneurs? Existing models of competition seem to suggest that (almost) no restriction can be placed on the equilibrium pattern of talents. To take the simplest example, if firms behave as price-takers producing a single homogeneous product, then all firms would prefer to enter the market with the highest market price. Free entry then implies that the equilibrium price must be the same in all markets, in which case all entrepreneurs are indifferent between all markets, and very little can be said about the relationship between market size and the efficiency levels of firms. ${ }^{1}$

In this paper, we propose an alternative model where each entrepreneur has a unique "idea": the knowledge to produce a distinct product. We begin by positing that the entrepreneurial input at a given location is "essential" (or the entrepreneurial span of control exhibits strongly diminishing returns across markets), so that each entrepreneur enters at most one market. Post-entry competition is therefore imperfect, and the intensity of competition in each market is the result of entrepreneurial entry decisions. We assume that the quality of an entrepreneur's idea varies with her talent. We then obtain a striking sorting result. In the unique equilibrium, the most capable entrepreneurs all enter the largest market, somewhat less capable entrepreneurs enter the next largest market, and so on, with the least talented group entering the smallest market. That is, the larger is the market, the more talented are its entrants.

This sorting result follows from little-known properties of standard models of imperfect competition with heterogeneous firms, and may be explained as follows. Free (but costly) entry implies that the toughness of price competition depends on the costs and benefits of the firms serving that market. If the market price were the same across all markets, then all firms would prefer to enter the

1. The same result would obtain in a Dixit-Stiglitz type model of monopolistic competition. There, each entrant in a given market faces the same residual demand curve of the form $D(p)=\psi p^{-\sigma}$, where $\sigma$ is a parameter of the utility function, and $\psi$ the endogenous demand level. Because each entrepreneur prefers to enter the market with the highest demand level $\psi$, free entry implies that, in equilibrium, each firm faces the same (residual) demand curve in all markets. 
larger market because they can expect to make more sales at a given price. So any equilibrium clearly entails lower prices in larger markets, so that some firms will prefer to enter the smaller markets. Which firms remain in the larger markets? Comparing two markets of different size, an entrepreneur now faces the following trade-off. In a larger market, she can expect to make greater sales (because there are more consumers) but her price-cost margins are narrower (because competition is endogenously more intense). A more efficient entrepreneur with lower marginal costs will have a larger price-cost margin and thus will benefit relatively more from the increased sales a larger market allows. In equilibrium, more efficient entrepreneurs will therefore enter the larger market, whereas less efficient entrepreneurs will enter the smaller market. Perhaps surprisingly, the selfselection of entrepreneurs into markets implies that the number of firms, and hence product variety, may actually be greater in a smaller market than in a larger one.

The sorting result continues to hold when entrepreneurs have to incur (weakly) higher fixed costs in larger markets. Sorting by talent also obtains when entrepreneurs can "export" their output to other markets, thereby incurring a unit transport cost or tariff. Depending on the level of transport costs, no entrepreneur may enter the smallest market(s). In the limit as transport costs become small-for instance, due to trade liberalization - entrepreneurs enter only the largest market, which has potentially important implications for trade policies.

In a dynamic extension, we analyze the relationship between churning of entrepreneurs and market size. To generate endogenous churning, we assume that the quality of an entrepreneur's idea changes stochastically over time, for example because of shocks to consumers' tastes. Provided that entrepreneurial efficiencies do not change at too fast a rate, the stationary equilibrium again exhibits sorting of the most efficient entrants into the largest markets. Entry and exit will occur simultaneously into the same industry at the same location: entrepreneurs with good draws continue to survive in the market while entrepreneurs with sufficiently bad draws decide to leave it and are replaced by new entrants. Most important, the churning rate of firms is higher in larger markets, and so firms' expected life span in such markets is shorter. Consequently, entrepreneurial firms tend to be younger in larger markets. This is consistent with the findings in Asplund and Nocke $(2000,2006)$.

As we noted, our paper is novel in considering how entrepreneurs decide which market to enter and departs from the existing literature in that our cross-industry predictions derive not from comparative statics exercises on a single-market model, but rather represent the equilibrium outcomes of a multi-market model. ${ }^{2}$

2. Although the problem may be viewed as a problem of matching entrepreneurs to heterogeneous markets, it differs from that analyzed in the standard matching literature (e.g., Roth and Sotomayor 1990) in at least two respects. First, this is a matching problem with externalities because each entrepreneur's value of entering one market depends on the entry decisions of other entrepreneurs. Second, the number of entrepreneurs that are matched to one market is not fixed but endogenous. 
A related literature considers the question of which members of the population should become entrepreneurs in a given market. Kihlstrom and Laffont (1979) consider the role of attitudes toward risk in entrepreneurial decision-making, which lies at the heart of the Knightian theory of entrepreneurship. We abstract from this aspect in our model of entrepreneurship and assume that entrepreneurs are risk-neutral profit maximizers. We also abstract from wealth constraints and imperfections in the capital market, which are explored in Evans and Jovanovic (1989). Holmes and Schmitz (1990) distinguish between entrepreneurial and managerial tasks to develop a Schultzian theory of entrepreneurship. In our model, these tasks are inseparable, and so a business cannot be transferred from an entrepreneur to a manager. Our theory of entrepreneurship is most closely related to that of Lucas (1978), where different agents have different levels of entrepreneurial talent. In Lucas's model, however, entrepreneurs are not free to choose between different markets, and thus he does not develop the sorting implications investigated here. Our paper is loosely connected to Rosen's (1981) model of "superstars" in which he explores the relationship between talent and earnings. ${ }^{3}$ As in Lucas's model, all agents behave as price takers and compete in the same market, and so the issue of self-selection into different markets does not arise.

The plan of this paper is as follows. In the next section, we present the baseline model where a population of heterogeneous entrepreneurs decides which market to enter. This model is analyzed in Section 3. There, we present the central sorting result of the paper: the larger the market, the more capable are its entrepreneurs. We also show that the number of active entrepreneurs (and thus product variety) may actually be smaller in a larger market. In Section 4, we analyze a stochastic dynamic extension of the baseline model and show that the churning rate of entrepreneurial firms is greater in larger markets. In Section 5, we consider two further extensions of our baseline model. First, we allow fixed costs to differ across markets. Second, we explore the implications of our theory for regional or international trade by allowing entrepreneurs to export their output to other markets. We conclude in Section 6.

\section{The Baseline Model of Entry}

We consider a model of $N$ imperfectly competitive markets which differ in their size, $S$. Markets are labeled in decreasing order of market size: $S_{1}>S_{2}>\cdots>$ $S_{N}$. Our preferred interpretation is that these are independent geographical markets within the same industry, and so $S_{i}$ may be thought of as the mass of consumers living in market $i$, which we take as given. Although we will henceforth adopt this interpretation, the reader may keep in mind an alternative interpretation,

3. Rosen (1982) analyzes the optimal assignment of talent to hierarchical positions within an organization and the implications for the distribution of earnings. 
namely, that different markets represent different industries. In that case, $S_{i}$ may be thought of as a measure of aggregate sales in industry $i{ }^{4}$ To isolate the effect of market size, we assume that markets are identical in all other respects (but see Section 5.1 for a generalization), which is a more realistic assumption under our preferred interpretation.

There is a population of (potential) entrepreneurs, each of whom may decide to enter one of the $N$ markets and to sell only in that market. To avoid multiplicity of equilibria and integer problems, we assume that this population forms a continuum of mass $M$. Each (potential) entrepreneur has a unique "idea": the know-how to produce one unique product. ${ }^{5}$ The quality of the entrepreneur's idea varies with her entrepreneurial talent. The entrepreneur's type is denoted by $c$, which may be the post-entry marginal cost of the entrepreneurial firm. Alternatively, an entrepreneur's type $c$ may be inversely related to the perceived quality of her product. In any event, a lower $c$ will be associated with better entrepreneurs. Any heterogeneity among entrepreneurs is assumed to be captured by this onedimensional type; firms are symmetric in all other respects. In the pool of potential entrants, the distribution of types is given by the cumulative distribution function $G(\cdot)$ with support $[0,1]$.

If an entrepreneur decides to enter a market, she has to pay a fixed production $\operatorname{cost} \varphi>0$. Because each entrepreneur offers a unique differentiated product, she faces a downward-sloping residual demand curve. The gross profit of a type- $c$ entrepreneur in market $i$ is given by

$$
S_{i} \Pi\left[c ; h\left(\mu_{i}\right)\right] \geq 0 .
$$

The (Borel) measure $\mu_{i}$ summarizes the distribution of entrepreneurial types in market $i$. For any interval $A$, the number $\mu_{i}(A)$ thus gives the mass of entrepreneurs active in market $i$ whose types fall into the interval $A$. The "intensity of competition" in market $i$ depends on the (endogenous) distribution of entrepreneurial types and is summarized by $h\left(\mu_{i}\right) \in \mathbb{R}$. Here, gross profits are proportional to market size for a given population of entrants: This holds quite generally in models of competition whenever firms produce at constant marginal costs and an increase in market size means a replication of the population of consumers (leaving the distribution of consumers' tastes and incomes unchanged) ${ }^{6}$

4. For instance, suppose each consumer has a two-tier utility function, where the first-tier utility function is over different goods (produced in different industries), and the second tier is over different varieties of the same good. Then, if the first-tier utility function is Cobb-Douglas, each consumer will spend a fixed fraction of his income on the varieties offered in industry $i$. In this case, industry sales are exogenously fixed by consumer preferences.

5. Our results would remain unchanged if we were to assume that each entrepreneur can produce the same fixed number of products.

6. This (standard) assumption can easily be relaxed, as discussed in Nocke (2003).

$$
\text { “zwu004060384” — 2006/7/6 — page } 934 \text { — \#6 }
$$


We impose the following assumptions on the reduced-form profit function $S \Pi[c ; h(\mu)]$.

Assumption 1. (MON) There is a $\bar{c}(\mu) \in[0,1]$ such that (i) $\Pi[c ; h(\mu)]=0$ for all $c \in[\bar{c}(\mu), 1]$, whereas (ii) $\Pi[c ; h(\mu)]$ is strictly decreasing in both arguments for $c<\bar{c}(\mu)$.

(DOM) If $\mu^{\prime}([0, c]) \geq \mu([0, c])$ for all $c \in[0,1]$, then $h\left(\mu^{\prime}\right) \geq h(\mu)$. If, in addition, the inequality is strict for some $c<\bar{c}(\mu)$, then $h\left(\mu^{\prime}\right)>h(\mu)$.

(CON) The functions $\Pi[c ; h(\mu)]$ and $h(\mu)$ are continuous. ${ }^{7}$

(COMP) For $h\left(\mu^{\prime}\right)>h(\mu)$, the profit ratio $\Pi\left[c ; h\left(\mu^{\prime}\right)\right] / \Pi[c ; h(\mu)]$ is strictly decreasing in $c$ on $[0, \bar{c}(\mu)]$.

(MON) says that gross profits are decreasing in entrepreneurial type $c$ and that a change in the distribution of active entrepreneurs that increases the toughness of competition (so that $h[\mu]$ increases) decreases profits. We allow for the possibility that sufficiently inefficient entrepreneurs (those with types $c>\bar{c}[\mu]$ ) cannot make positive gross profits. (DOM) says that competition is more intense (in that $h[\mu]$ is larger) if the mass of active firms is larger and the entrepreneurs are more efficient. The condition ensures that additional entry of entrepreneurs reduces profits, and hence the value of an entrant. (CON) is a technical condition. (COMP) says that any change in the distribution of active types that makes competition more intense (and reduces the profits of all types), causes the gross profit of less efficient types to fall by a larger fraction than that of more efficient types. ${ }^{8}$ This property will play a key role for the central sorting result.

To ensure that, in equilibrium, there is a positive mass of entrants in each market and some entrepreneurs (obviously, the least capable ones) do not enter any market, we assume that unbounded entry drives profits down to zero,

$$
\lim _{\lambda \rightarrow \infty} S \Pi[c ; h(\lambda \mu)]=0 \quad \text { for all } c \in[0,1],
$$

and that the total mass of potential entrepreneurs, $M$, is sufficiently large. Further, we posit that the fixed $\operatorname{cost} \varphi$ is sufficiently small so that entering an empty market is preferred to not entering any market:

$$
S_{N} \Pi\left[1 ; h\left(\mu^{0}\right)\right]>\varphi,
$$

where $\mu^{0}$ is the null measure, that is, $\mu^{0}([0,1]) \equiv 0$.

7. We endow the set of Borel measures on $[0,1]$ with the topology of weak* convergence.

8. This is equivalent to assuming that (the absolute value of) the elasticity of the gross profit function with respect to $c$ increases as the market becomes more competitive.

$$
\text { “zwu004060384” — 2006/7/6 — page 935 — \#7 }
$$


Formally, the model may be viewed as an anonymous game with a continuum of players. An entrepreneur's pure strategy $s$ is a mapping $s:[0,1] \rightarrow$ $\{0,1, \ldots, N\}$, where $s(c)=0$ means "do not enter", and $s(c)=i, i=1, \ldots, N$, stands for "enter market $i$." We seek the pure-strategy Nash equilibrium of this game.

Our assumptions on the reduced-form profit function hold in many standard models of symmetric and non-localized competition. It is straightforward to verify this for the linear demand model subsequently described. In Nocke (2005), we show that the homogeneous-good Cournot model (with a finite number of firms that differ in their constant marginal costs) satisfies all of our assumptions on the reduced-form profit function under very mild restrictions on demand.

EXAMPLE 1 (Linear Demand). There is a continuum of identical consumers (of mass $8 S$ ) with utility function

$$
U=\int_{0}^{n}\left(x(k)-x^{2}(k)-2 \sigma \int_{0}^{n} x(k) x(l) d l\right) d k+H,
$$

where $x(k)$ is the consumption of variety $k \in[0, n]$, and $H$ the consumption of the Hicksian composite commodity (the price of which is normalized to one). The parameter $\sigma \in(0,1)$ measures the substitutability between different varieties. The linear-quadratic utility function gives rise to the well-known linear demand system. ${ }^{9}$ A type- $c$ entrepreneur has marginal cost $c$, independently of output. As we show in the technical appendix (Nocke 2005) the equilibrium profit of a type- $c$ entrepreneur is given by

$$
S \Pi[c ; h(\mu)]= \begin{cases}S[\bar{c}(\mu)-c]^{2} & \text { if } c \leq \bar{c}(\mu), \\ 0 & \text { otherwise }\end{cases}
$$

where

$$
\bar{c}(\mu)=\frac{1+\sigma \int_{0}^{\bar{c}(\mu)} z \mu(d z)}{1+\sigma \mu([0, \bar{c}(\mu)])}
$$

denotes the marginal type such that all less efficient types make zero sales even when pricing at marginal cost. The intensity of price competition $h(\mu)$ is negatively related to this marginal type $\bar{c}(\mu)$.

\section{Endogenous Sorting of Entrepreneurs}

In this section, we show that the unique equilibrium exhibits sorting of entrepreneurs: The most capable entrepreneurs all enter the largest market, less

9. The discrete version of the utility function goes back to Bowley (1924). The linear demand system is widely used in oligopoly models; see Vives (1999).

$$
\text { “zwu004060384” — 2006/7/6 — page } 936 \text { - \#8 }
$$


capable entrepreneurs enter the next largest market, and so on. This implies that the mass of active entrepreneurs and, hence, product variety may actually be smaller in a larger market.

Because the fixed $\operatorname{cost} \varphi$ is assumed to be small, and the size $M$ of the pool of entrepreneurs is assumed to be large, any equilibrium has the following features: There is a positive mass of entrepreneurs in each market and a positive mass of entrepreneurs who prefer not to enter any market. Denote by $\mu_{i}$ the measure of entrepreneurs who decide to enter market $i$ in equilibrium. Then, we must have the following ordering:

$$
h\left(\mu_{1}\right)>h\left(\mu_{2}\right)>\cdots>h\left(\mu_{N}\right) .
$$

That is, the larger is the market, the larger is $h(\mu)$, and so the more intense is competition. To see this, suppose otherwise that there are markets $i$ and $j>i$ such that $h\left(\mu_{i}\right) \leq h\left(\mu_{j}\right)$. This implies that all entrepreneurs (who are sufficiently efficient so as to make positive sales) strictly prefer to enter market $i$ rather than market $j$ :

$$
S_{i} \Pi\left[c ; h\left(\mu_{i}\right)\right] \geq S_{i} \Pi\left[c ; h\left(\mu_{j}\right)\right]>S_{j} \Pi\left[c ; h\left(\mu_{j}\right)\right], \quad c \in\left[0, \bar{c}\left(\mu_{j}\right)\right],
$$

where the first inequality follows from $h\left(\mu_{i}\right) \leq h\left(\mu_{j}\right)$ and the second inequality from $S_{i}>S_{j}$. However, if all entrepreneurs preferred market $i$ over market $j$, no entrepreneur would decide to enter market $j$, and so we could not have $h\left(\mu_{i}\right) \leq$ $h\left(\mu_{j}\right)$.

Consider the ratio of gross profit in market $i$ over that in market in $j$,

$$
\Psi_{i j}(c) \equiv \frac{S_{i} \Pi\left[c ; h\left(\mu_{i}\right)\right]}{S_{j} \Pi\left[c ; h\left(\mu_{j}\right)\right]} .
$$

Suppose that entrepreneurial type $c_{i j}$ is indifferent between entering market $i$ and market $j>i$, and so $\Psi_{i j}\left(c_{i j}\right)=1$. Because $h\left(\mu_{i}\right)>h\left(\mu_{j}\right)$, condition (COMP) implies that the profit ratio $\Psi_{i j}(c)$ is strictly decreasing in $c$ for $c<\bar{c}\left(\mu_{i}\right)$. Hence, all entrepreneurs more capable than $c_{i j}$ strictly prefer to enter (the larger but more competitive) market $i$, whereas less capable entrepreneurs strictly prefer to enter (the smaller but less competitive) market $j$. Because there can be at most one entrepreneur (with positive profit) who is indifferent between the two markets, we obtain the central sorting result of this paper.

PROPOSITION 1. There exists a unique equilibrium. In equilibrium, there are marginal types $0 \equiv c_{0}<c_{1}<\cdots<c_{N}$ such that (almost) all entrepreneurs of type $c \in\left[c_{i-1}, c_{i}\right]$ enter market $i$, while (almost) all entrepreneurs of type $c \in\left[c_{N}, 1\right]$ do not enter any market. Hence, each entrepreneur in a given market is more capable than any entrepreneur in a smaller market.

See the appendix for the proof of the proposition.

$$
\text { “zwu004060384" — 2006/7/6 — page } 937 \text { — \#9 }
$$


The proposition shows that the relationship between the characteristics of a market and the talents of its entrepreneurs takes a surprisingly extreme form: the larger is the market, the more talented are its entrepreneurs in that each entrepreneur in a large market is more efficient than any entrepreneur in a smaller market. Consequently, the total mass of entrepreneurs in market $i$ whose types fall into the interval $[0, z]$ is given by

$$
\mu_{i}([0, z])= \begin{cases}0 & \text { if } z<c_{i-1} \\ M\left[G(z)-G\left(c_{i-1)}\right]\right. & \text { if } z \in\left[c_{i-1}, c_{i}\right) \\ M\left[G\left(c_{i}\right)-G\left(c_{i-1)}\right]\right. & \text { if } z \geq c_{i}\end{cases}
$$

The sorting result obtains because more capable entrepreneurs are better off in a larger and endogenously more competitive market whereas less capable entrepreneurs are better off in a smaller and hence less competitive market. To obtain a better intuition, suppose that a type- $c$ entrepreneur produces at constant marginal cost $k(c)$, where $k^{\prime}(c)>0$. Gross profit then takes the form $S \Pi[c ; h(\mu)]=\{p[c ; h(\mu)]-k(c)\} q[c ; h(\mu), S]$. Suppose type $c_{i j}$ is indifferent between entering market $i$ and (the smaller) market $j>i$. Intuitively, one would expect that type $c_{i j}$ would charge a lower price in the endogenously more competitive market $i$ than in market $j$, i.e., $p\left[c_{i j} ; h\left(\mu_{i}\right)\right]<p\left[c_{i j} ; h\left(\mu_{j}\right)\right]$. Indeed, as the following proposition shows, condition (COMP) is equivalent to requiring that an increase in the toughness of price competition (an increase in $h[\mu]$ ) results in lower equilibrium prices for all types with positive sales. ${ }^{10}$

PROPOSITION 2. Suppose (entrepreneurial) firms have constant marginal costs $k(c)$, where $k^{\prime}(c)>0$, so that the gross profit of a type-c firm can be written as $S \Pi[c ; h(\mu)]=\{p[c ; h(\mu)]-k(c)\} q[c ; h(\mu), S]$, where $p[c ; h(\mu)]$ is equilibrium price, and $q[c ; h(\mu), S]$ equilibrium output. Then, assumption $(C O M P)$ holds if and only if, for $c \in[0, \bar{c}(\mu)]$, the equilibrium price $p[c ; h(\mu)]$ is decreasing in the intensity of price competition $h(\mu)$.

See the appendix for a formal proof.

Because entrepreneurial type $c_{i j}$ is indifferent between entering market $i$ and market $j$, but would charge a lower price in the more competitive market $i$, it follows that she would sell a larger quantity in that market: $q\left[c_{i j} ; h\left(\mu_{i}\right), S_{i}\right]>$ $q\left[c_{i j} ; h\left(\mu_{j}\right), S_{j}\right]$. Do entrepreneurs who are marginally more capable than type $c_{i j}$ prefer to enter the smaller or the larger market? From the envelope theorem, the additional profit from a marginal decrease in $c$ is equal to $k^{\prime}(c) q$, which is

10. Note, however, that the Dixit-Stiglitz model (with a continuum of firms with constant marginal costs) does not have this property; there, firms' markups are completely independent of the state of competition, and so $\Pi\left[c ; h\left(\mu^{\prime}\right)\right] / \Pi[c ; h(\mu)]$ is independent of $c$, violating (COMP). 
increasing in output $q$. Since $q\left[c_{i j} ; h\left(\mu_{i}\right), S_{i}\right]>q\left[c_{i j} ; h\left(\mu_{j}\right), S_{j}\right]$, it follows that an entrepreneur who is slightly more efficient than type $c_{i j}$ strictly prefers to enter market $i$ rather than the smaller market $j$, while a slightly less talented entrepreneur strictly prefers to enter the smaller market. Hence, more talented entrepreneurs sort into larger markets than less talented entrepreneurs.

As in Lucas (1978), the size distribution of firms in a given market is determined by the underlying distribution of entrepreneurial talent (namely, the distribution function $G[\cdot]$ ). Although our theory does not impose testable restrictions on the size distribution within a given market, it does allow us to make predictions across markets. Suppose we measure firm size by output $q[c ; h(\mu), S]$ and assume that output is decreasing in the entrepreneur's type $c$ (which indeed it is if marginal costs are increasing in $c$ ). As discussed above, any entrepreneur who is indifferent between entering two markets would produce a greater output in the larger market. Because more talented entrepreneurs enter larger markets, our model predicts that firms located in larger markets are larger than those in smaller markets.

Let us now reconsider the relationship between market size and the number of entrants. Following Bresnahan and Reiss (1991), a number of researchers have found that the ratio between the number of firms and market size is smaller in larger markets. This finding has been interpreted as evidence for the existence of the price competition effect: An increase in market size typically leads to more entry, and then the price competition effect implies a fall in price-cost margins. Hence, in larger markets, market size has to increase by a larger amount so as to sustain an additional firm in the market. The existing studies have implicitly assumed that the distribution of entrants' efficiency levels does not vary across markets. In particular, they have not allowed for self-selection of entrepreneurs at the entry stage.

In our model, the sorting effect may reinforce the price competition effect: Because more efficient firms self-select into larger markets, entry causes pricecost margins to fall "at a much faster rate" with market size than without sorting. In fact, the sorting effect may be so strong that a larger market may have fewer entrepreneurs and, hence, less product variety to offer than a smaller market. ${ }^{11}$ This counterintuitive relationship may arise because competition in a market may be more intense for two reasons: (i) there is a larger population of active

11. In recent work, Vives (2005) analyzes an oligopoly model where identical firms decide how much to invest in cost reduction before competing in prices or quantities. For a given level of $R \& D$ spending, the number of entrants rises with market size, but less than proportionately because of the price competition effect. An increase in market size, however, raises firms' R\&D spending, leaving less room for entrants. The latter effect may dominate, and so the number of entrants may fall with an increase in market size. A similar result has been obtained in a parametric example by Sutton (1991). Our paper shows that a nonmonotonic relationship between market size and product variety may arise not only in "endogenous sunk cost" industries, but also in "exogenous sunk cost" industries, provided entrepreneurs can self-select into markets. 
entrepreneurs, and (ii) the active entrepreneurs are more efficient. Moreover, the endogenous intensity of price competition changes continuously with market size, whereas the average efficiency of its entrepreneurs may change discontinuously. Suppose that the difference in size between markets $i$ and $j>i$ is small. Then, competition in market $i$ is not much more intense than in market $j$ in the sense that $h\left(\mu_{i}\right)-h\left(\mu_{j}\right)$ is small. But entrepreneurs in market $i$ are much more capable than those in $j$, and so we may have

$$
\mu_{i}([0,1])=M\left[G\left(c_{i}\right)-G\left(c_{i-1}\right)\right]<M\left[G\left(c_{j}\right)-G\left(c_{j-1}\right)\right]=\mu_{j}([0,1]),
$$

even though $h\left(\mu_{i}\right)>h\left(\mu_{j}\right)$. This is illustrated in the following numerical example.

EXAMPLE 2 (Linear Demand). Consider the linear demand example. Suppose there are only two markets, $N=2$, and entrepreneurial types are uniformly distributed on the unit interval, that is, $G(c)=c$ for $c \in[0,1]$. In the unique equilibrium, the marginal types $c_{1}$ and $c_{2}>c_{1}$ are determined by

$$
\begin{aligned}
S_{1}\left(\frac{1+\sigma M c_{1}^{2} / 2}{1+\sigma M c_{1}}-c_{1}\right)^{2} & =S_{2}\left(\frac{1+\sigma M\left(c_{2}^{2}-c_{1}^{2}\right) / 2}{1+\sigma M\left(c_{2}-c_{1}\right)}-c_{1}\right)^{2}, \\
S_{2}\left(\frac{1+\sigma M\left(c_{2}^{2}-c_{1}^{2}\right) / 2}{1+\sigma M\left(c_{2}-c_{1}\right)}-c_{2}\right)^{2} & =\varphi .
\end{aligned}
$$

Assume that $\varphi=1, \sigma M=2, S_{1}=50$, and $S_{2}=20$. The marginal types are then given by $c_{1} \approx 0.360$ and $c_{2} \approx 0.606$. As expected, the total mass of entrepreneurial firms is larger in the larger market: $\mu_{1}([0,1]) / M=c_{1} \approx 0.360$, whereas $\mu_{2}([0,1]) / M=\left(c_{2}-c_{1}\right) \approx 0.246$. Assume now that the smaller market 2 is larger, $S_{2}=30$. In this case, $c_{1} \approx 0.300$ and $c_{2} \approx 0.609$. Perhaps surprisingly, there are more (but less capable) entrepreneurs in the smaller market: $\mu_{1}([0,1]) / M \approx 0.300<0.309 \approx \mu_{2}([0,1]) / M$. More generally, whenever the difference in size between any two markets (as measured by $S_{i}-S_{i+1}$ ) is sufficiently large, there is a positive correlation between market size and the number of entrepreneurs (or product variety) across markets. If, however, the differences are sufficiently small (in that $S_{1}-S_{N}$ is small), there is a negative cross-sectional correlation.

Empirical Evidence. Following Sveikauskas (1975) and Henderson (1986), there is an empirical literature on productivity differences across cities and regions. A robust finding is that total factor productivity is higher in larger cities or more densely populated regions. In a recent paper using Japanese data, Davis and Weinstein (2001) find that, ceteris paribus, a doubling of region size raises 
productivity by $3.5 \%$. Syverson (2004) shows that cement plants are more efficient in more densely populated U.S. metropolitan areas. The urban and regional economics literature has traditionally attributed these productivity differences to agglomeration externalities. The present model suggests that a different force may be at work: more productive firms may endogenously select into larger markets. By failing to account for self-selection, however, the empirical literature may overestimate the role of externalities.

\section{The Dynamic Model with Entry and Exit}

Rates of firm turnover differ substantially across industries. These differences are similar from one country to another, and stable over time. Although these crossindustry differences are not yet very well understood, there is a small number of models that attempt to relate firm turnover to observable industry characteristics. For example, Hopenhayn (1992) and Lambson (1991) consider the effect of sunk costs in a dynamic model with price-taking firms. Asplund and Nocke (2006) analyze the impact of market size and sunk costs in a related dynamic model of imperfect competition, and show that turnover rates are positively related to market size. In these single-industry models, firms are ex ante identical, and it is implicitly assumed that the distribution of entrants' characteristics (such as entrepreneurial "talent") are identical across markets.

In this section, we re-examine the relationship between market size and turbulence but take a different approach from the existing literature: We analyze the impact of market size on firm turnover in a multi-market model where the distribution of entrants' capabilities may vary endogenously across markets.

\subsection{The Dynamic Model}

We assume that time is discrete, and that firms have an infinite horizon and a common discount factor $\delta \in[0,1) .{ }^{12}$ In each period, there is a mass $M$ of young entrepreneurs whose current types are distributed according to $G(\cdot)$. Knowing her current type, a young entrepreneur decides whether to enter a market and, if so, which one of the $N$ markets. As before, each entrepreneur can enter at most one market. To generate turbulence, we assume that the quality of an entrepreneur's idea changes stochastically over time. This may be due to shocks to consumers' tastes for the entrepreneur's product. Specifically, with probability $\alpha \in(0,1)$, the entrepreneur will be of the same efficiency as in the last period, whereas with the remaining probability $1-\alpha$ she gets a new draw of her type from a

12. If the probability of the entrepreneur's (physical) death in a period is $\gamma$ and the factor of time preference is $\tilde{\delta}$, the effective discount factor becomes $\delta=\tilde{\delta}(1-\gamma)$. 
continuous and strictly increasing distribution function $F(\cdot)$. A currently more efficient entrepreneur is more likely to be efficient in the future than a currently less efficient entrepreneur, and this persistence is measured by the probability $\alpha$.

The timing in each period is as follows. At the first stage, young entrepreneurs (potential entrants) and old entrepreneurs (incumbents) learn the realization of their current types. At the second stage, young entrepreneurs make their entry decisions and incumbents decide whether exit the market. Entrepreneurs who decide not to be active take up an outside option, normalized to zero. Re-entry after exit is not possible. We assume that only young entrepreneurs are (geographically) mobile, which implies that old entrepreneurs cannot switch from one market to another. At the third and final stage, the active entrepreneurs in a given market compete and obtain a gross profit $S \Pi[c ; h(\mu)]$, which depends on their current type $c$, the endogenous intensity of price competition $h(\mu)$, and the size of their market, $S$. Moreover, active entrepreneurs pay a fixed per-period $\operatorname{cost} \varphi>0$, which ensures that the least efficient entrants will not enter any market and that sufficiently inefficient incumbents will decide to leave the market. We impose the same structure on the gross profit function as in the baseline model: $(\mathrm{MON}),(\mathrm{CON}),(\mathrm{DOM})$, and (COMP) are assumed to hold.

\subsection{Stationary Equilibrium}

We confine attention to stationary equilibria in which the entrepreneurial entry and exit strategies, and hence the distribution of active types in each market, are time-independent.

Let $V(c ; h(\mu), S)$ denote the value (at stage 2) of a type- $c$ entrepreneur in a market of size $S$, where the distribution of types is given by $\mu$. Because the entrepreneur has the option to leave the market, this value satisfies

$$
V[c ; h(\mu), S]=\max \{\bar{V}(c ; h(\mu), S), 0\},
$$

where

$$
\begin{aligned}
\bar{V}[c ; h(\mu), S]= & S \Pi[c ; h(\mu)]-\varphi \\
& +\delta\left\{\alpha V[c ; h(\mu), S]+(1-\alpha) \int_{0}^{1} V[u ; h(\mu), S] F(d u)\right\}
\end{aligned}
$$

is the value conditional on staying in the market in the current period, and behaving optimally thereafter. It is straightforward to see that $\bar{V}[c ; h(\mu), S]$ is continuous and decreasing in $c$ on $[0, \bar{c}(\mu)]$. Let $c^{*}(\mu, S)$ denote the optimal exit policy: All more efficient types prefer to stay in the market, while all less 
efficient types prefer to leave the market and take up the outside option, namely, $\bar{V}\left[c^{*}(\mu, S) ; h(\mu), S\right]=0$. If $c^{*}(\mu, S)<\bar{c}(\mu)$ (as we assume for the moment), $c^{*}(\mu, S)$ is unique. The conditional value can be rewritten as

$$
\begin{aligned}
\bar{V}[c ; h(\mu), S]= & \frac{1}{1-\delta \alpha}\left\{S \Pi[c ; h(\mu)]-\varphi+\frac{\delta(1-\alpha) F\left[c^{*}(\mu, S)\right]}{1-\delta \alpha-\delta(1-\alpha) F\left[c^{*}(\mu, S)\right]}\right. \\
& \left.\times \int_{0}^{c^{*}(\mu, S)}[S \Pi(u ; h(\mu))-\varphi] F(d u)\right\},
\end{aligned}
$$

and so $\bar{V}[c ; h(\mu), S] \approx\{S \Pi[c ; h(\mu)]-\varphi\} /[1-\delta \alpha]$ if $\delta(1-\alpha) /(1-\delta) \approx 0$. That is, as the parameter of cost persistence, $\alpha$, goes to one (or the discount factor $\delta$ goes to zero), a firm's value-conditional on staying in the market for another period-becomes proportional to its current gross profit. We obtain the following result.

PROPOSITION 3. Suppose that costs are persistent over time (or the discount factor is small) such that $\delta(1-\alpha) /(1-\delta)$ is sufficiently small. Then, the unique stationary equilibrium of the dynamic model exhibits sorting of entrepreneurs by types. That is, there exist marginal types $0 \equiv c_{0}<c_{1}<\cdots<c_{N}$ such that (almost) all entrepreneurs of type $c \in\left[c_{i-1}, c_{i}\right)$ enter market $i$, while (almost) all entrepreneurs of type $c \in\left[c_{N}, 1\right]$ do not enter any market.

See the appendix for a formal proof.

Note that while the sorting result applies to new entrants, it is no longer true that any entrepreneur in a larger market is more talented than all entrepreneurs in smaller markets. But, as we will show below, a weaker result holds: The least efficient entrepreneur in a larger market is more talented than the least efficient entrepreneur in a smaller market.

From now on, let us assume that the unique stationary equilibrium exhibits sorting of types, as it indeed does under the condition of Proposition 3. For any markets $i$ and $j$, there exists a unique type $c_{i j}$ such that $\bar{V}\left[c_{i j} ; h\left(\mu_{i}\right), S_{i}\right]=$ $\bar{V}\left[c_{i j} ; h\left(\mu_{j}\right), S_{j}\right] \geq 0$. In the stationary equilibrium, the total mass of entrants per period is equal to the total mass of exiting firms:

$$
\left[G\left(c_{i}\right)-G\left(c_{i-1}\right)\right] M=(1-\alpha)\left\{1-F\left[c^{*}\left(\mu_{i}, S_{i}\right)\right]\right\} \mu_{i}([0,1]) .
$$

The total mass of entrepreneurs active in market $i$ is then given by

$$
\mu_{i}([0,1])=\frac{\left[G\left(c_{i}\right)-G\left(c_{i-1}\right)\right] M}{(1-\alpha)\left[1-F\left(c^{*}\left(\mu_{i}, S_{i}\right)\right)\right]} .
$$

Although the value of the least efficient entrant in the smallest market is zero, it is strictly positive in any other market $i<N: \bar{V}\left[c_{i} ; h\left(\mu_{i}\right), S_{i}\right]>0=$ 
$\bar{V}\left[c_{N} ; h\left(\mu_{N}\right), S_{N}\right]$. Because the value of the least efficient incumbent (who is just indifferent between exiting and staying in the market) is zero, it follows that the marginal incumbent is less efficient than the least efficient entrant in that market (except for the smallest market):

$$
c^{*}\left(\mu_{i}, S_{i}\right)>c_{i} \quad \text { for } i=1, \ldots, N-1, \text { and } c^{*}\left(\mu_{N}, S_{N}\right)=c_{N} .
$$

In each period, a share

$$
\theta_{i} \equiv(1-\alpha)\left\{1-F\left[c^{*}\left(\mu_{i}, S_{i}\right)\right]\right\}
$$

of entrepreneurs exit market $i$. Given our simple stochastic process, the probability of exit is independent of the entrepreneurial type (within the same market), and so $\theta_{i}$ is equal to each incumbent's probability of exit in market $i$. We will henceforth use $\theta$ as our measure of firm turnover. As equation (4) shows, the churning rate $\theta$ varies across markets if different exit policies $c^{*}(\mu, S)$ are used in different markets: The tougher is the exit policy (the smaller is $c^{*}[\mu, S]$ ), the higher is the churning rate $\theta$.

We now claim that the marginal incumbent in market $i$ is more efficient in larger markets, namely, $c^{*}\left(\mu_{i}, S_{i}\right)$ is increasing in $i$. To see this, recall that (i) entrepreneurial type $c_{i}, i<N$, is indifferent between entering the larger market $i$ and the smaller market $i+1$, that is, $\bar{V}\left[c_{i} ; h\left(\mu_{i}\right), S_{i}\right]=\bar{V}\left[c_{i} ; h\left(\mu_{i+1}\right), S_{i+1}\right]$, and that (ii) from equation (3), the marginal incumbent in market $i<N$ is less efficient than the least efficient entrant in that market, that is, $c^{*}\left(\mu_{i}, S_{i}\right)>c_{i}$. From the single-crossing property of $\bar{V}$, it then follows that entrepreneurial type $c^{*}\left(\mu_{i}, S_{i}\right)$ is better off in the less competitive market $i+1$ than in market $i$, and so

$$
0=\bar{V}\left[c^{*}\left(\mu_{i}, S_{i}\right) ; h\left(\mu_{i}\right), S_{i}\right]<\bar{V}\left[c^{*}\left(\mu_{i}, S_{i}\right) ; h\left(\mu_{i+1}\right), S_{i+1}\right] .
$$

Because $\bar{V}\left[c^{*}\left(\mu_{i+1}, S_{i+1}\right) ; h\left(\mu_{i+1}\right), S_{i+1}\right]=0$, and the value function $\bar{V}$ is strictly decreasing in its first argument, it follows that $c^{*}\left(\mu_{i+1}, S_{i+1}\right)>c^{*}\left(\mu_{i}, S_{i}\right)$.

The equilibrium exit policy is tougher in larger markets, and so the churning rate $\theta_{i}$ is higher in larger markets. We summarize our result on turnover in the following proposition.

PROPOSITION 4. Suppose the stationary equilibrium exhibits sorting by types: For any two markets $i$ and $j$, there exists a unique type $c_{i j}$ such that $\bar{V}\left[c_{i j} ; h\left(\mu_{i}\right), S_{i}\right]=\bar{V}\left[c_{i j} ; h\left(\mu_{j}\right), S_{j}\right] \geq 0$. Then, the marginal entrepreneur is less efficient in smaller markets, that is, $c^{*}\left(\mu_{i}, S_{i}\right)$ is increasing in $i$. Hence, the equilibrium churning rate is larger in larger markets, that is, $\theta_{i}$ is decreasing in $i$. 
The proposition implies that the range of efficiency levels of firms within a market is smaller in larger markets. ${ }^{13}$ Moreover, in smaller markets, the distribution of entrepreneurial types is shifted towards less efficient types in the sense of first-order stochastic dominance since entrants are less efficient in smaller markets, and incumbents' exit policy is less tough.

There is a close link between firm turnover and the age distribution of businesses. Intuition suggests that markets with higher churning rates have on average younger firms. Let the period- $t$ age of a firm that entered in period $t^{e} \leq t$ be given by $t-t^{e}+1$. Then, in stationary equilibrium, the average firm age in market $i$ is equal to $1 / \theta_{i}$. Furthermore, the share of firms active in market $i$ whose age is less than or equal to $y \geq 1$ is given by

$$
\frac{\sum_{t=0}^{y-1}\left(1-\theta_{i}\right)^{t}}{\sum_{t=0}^{\infty}\left(1-\theta_{i}\right)^{t}}=1-\left(1-\theta_{i}\right)^{y} .
$$

For $y>1$, this expression is increasing in $\theta_{i}$. Because the churning rate $\theta_{i}$ is decreasing in $i$, we obtain the following result.

COROLlaRY 1. Suppose the condition of Proposition 4 holds. Then, in stationary equilibrium, firms are on average older in smaller markets. Specifically, the age distribution of firms in smaller markets first-order stochastically dominates that in larger markets.

It is straightforward to show that the (conditional) value of any type is the same across markets if firms behave as price takers or compete à la Dixit-Stiglitz. In this case, sorting of firms does not obtain, and the turnover rate and age distribution do not vary across markets.

Empirical Evidence. How can our predictions on churning rates be tested empirically? As Sutton (1997) pointed out, the magnitude of the underlying fluctuations in the pattern of demand (or technology) is likely to vary greatly across industries, but it is very difficult to measure this factor or to control for its impact empirically. Fortunately, an attractive feature of our theory is that its predictions on firm turnover can be tested by comparing churning rates of local service firms in different-sized local markets within the same industry. This should control for many of those factors that would otherwise differ across industries. This is the route taken in Asplund and Nocke (2000), where we use data on driving schools in Sweden. Estimating the probability of exit in a Probit model, we find some supportive evidence for the prediction that churning rates are higher in larger municipalities. In more recent work, Asplund and Nocke (2006), we analyze

13. This is consistent with the empirical evidence on cement plants; see Syverson (2004). 
the age distribution of hairdressers in Sweden. Using non-parametric tests, we find that the age distribution of firms in smaller markets first-order stochastically dominates the age distribution in larger markets, as predicted by our theory.

\section{Robustness and Extensions}

In this section, we consider two extensions of our baseline model. First, we investigate the robustness of our predictions by allowing markets to differ not only in their size but also in the level of fixed costs. Second, we extend the baseline model by allowing entrepreneurs to export their product from their home market to all other markets at a unit transport cost or tariff. To keep this section short and to the point, we analyze these extensions for the case of the linear demand model. However, we will also briefly remark on what properties of the reduced-form profit function are sufficient to obtain our results.

\subsection{Sorting of Entrepreneurs when Markets Differ in Size and Fixed Costs}

So far, we have assumed that markets differ only in their size but are identical otherwise. This served to make our point most forcefully: Everything else being equal, the most capable entrepreneurs will enter the largest market, while less capable entrepreneurs will self-select into smaller markets. In empirical applications, however, markets may differ not only in their size but also along other dimensions. This problem arises in particular under the alternative interpretation where different markets represent different industries (rather than different local markets within the same industry). We now show that our sorting result continues to hold when fixed costs are non-negatively related to market size.

Suppose that demand in each market $i$ is linear, and so the gross profit of a type- $c$ entrepreneur who produces at marginal cost $c$ in market $i$ is given by

$$
\begin{aligned}
S_{i} \Pi\left(c ; h\left(\mu_{i}\right)\right) & =\left\{p\left(c ; h\left[\mu_{i}\right]\right)-c\right\} q\left[c ; h\left(\mu_{i}\right), S_{i}\right] \\
& = \begin{cases}S_{i}\left(\bar{c}\left(\mu_{i}\right)-c\right)^{2} & \text { if } c \leq \bar{c}\left(\mu_{i}\right), \\
0 & \text { otherwise. }\end{cases}
\end{aligned}
$$

(Recall that the intensity of price competition in market $i, h\left[\mu_{i}\right]$, is inversely related to the marginal type $\bar{c}\left[\mu_{i}\right]$.) We assume that fixed costs are weakly larger in larger markets, that is, $\varphi_{i+1} \geq \varphi_{i}$ for any $i<N$. For simplicity, we posit that differences in fixed costs across markets are not too large (relative to differences in market size) so that a positive mass of entrepreneurs will enter each market in equilibrium. 
Consider an entrepreneur of type $c_{i j}$ who is indifferent between entering market $i$ and the smaller market $j>i$,

$$
\begin{aligned}
\psi\left(c_{i j}\right) & \equiv\left\{S_{i} \Pi\left[c_{i j} ; h\left(\mu_{i}\right)\right]-\varphi_{i}\right\}-\left\{S_{j} \Pi\left[c_{i j} ; h\left(\mu_{j}\right)\right]-\varphi_{j}\right\} \\
& =\left\{S_{i}\left[\bar{c}\left(\mu_{i}\right)-c_{i j}\right]^{2}-\varphi_{i}\right\}-\left\{S_{j}\left[\bar{c}\left(\mu_{j}\right)-c_{i j}\right]^{2}-\varphi_{j}\right\}=0 .
\end{aligned}
$$

We now want to show that all entrepreneurial types more capable than $c_{i j}$ will then strictly prefer to enter the larger market $i$, that is, $\psi^{\prime}\left(c_{i j}\right)<0$. To see this, note that

$$
\begin{aligned}
\psi^{\prime}\left(c_{i j}\right) & =-q\left[c_{i j} ; h\left(\mu_{i}\right), S_{i}\right]+q\left[c_{i j} ; h\left(\mu_{j}\right), S_{j}\right] \\
& =-2 S_{i}\left[\bar{c}\left(\mu_{i}\right)-c_{i j}\right]+2 S_{j}\left[\bar{c}\left(\mu_{i}\right)-c_{i j}\right],
\end{aligned}
$$

which is negative if and only if type $c_{i j}$ would produce a larger output in market $i$ than in the smaller market $j$. We distinguish between two cases. (i) If competition is not more intense in market $i$ than in the smaller market $j$, namely, $\bar{c}\left(\mu_{i}\right) \geq$ $\bar{c}\left(\mu_{j}\right)$, it follows from (5) and $S_{i}>S_{j}$ that $\psi^{\prime}\left(c_{i j}\right)<0$. (ii) If competition is more intense in the larger market $i$, namely, $\bar{c}\left(\mu_{i}\right)<\bar{c}\left(\mu_{j}\right)$, then from (COMP) and Proposition 2, we know that type $c_{i j}$ would charge a lower price in the more competitive market $i$, that is,

$$
p\left[c_{i j} ; h\left(\mu_{i}\right)\right]=\frac{\bar{c}\left(\mu_{i}\right)+c_{i j}}{2}<\frac{\bar{c}\left(\mu_{j}\right)+c_{i j}}{2}=p\left[c_{i j} ; h\left(\mu_{j}\right)\right] .
$$

By definition, type $c_{i j}$ would make the same net profit in both markets. Because fixed costs are weakly larger in market $i$, it follows that her gross profit in market $i$ would be larger than or equal to that in the smaller market $j$. But because she would charge a lower price in market $i$, we can conclude that she would produce a larger quantity in that market, and so $\psi^{\prime}\left(c_{i j}\right)<0$. Hence, our sorting result of Proposition 1 extends to the case where fixed costs and market size are positively related.

PROPOSITION 5. Suppose fixed costs are weakly larger in larger markets, that is, $\varphi_{i+1} \geq \varphi_{i}$ for all $i \in\{1, \ldots, N-1\}$. Then, in equilibrium there are marginal types $0 \equiv c_{0}<c_{1}<\cdots<c_{N}$ such that (almost) all entrepreneurs of type $c \in\left[c_{i-1}, c_{i}\right)$ enter market $i$, while (almost) all entrepreneurs of type $c \in\left[c_{N}, 1\right]$ do not enter any market. Hence, each entrepreneur in a given market is more capable than any entrepreneur in a smaller market.

Although we have derived this result for our static baseline model, it is straightforward to see that the same sorting result applies to our dynamic model as long as $\delta(1-\alpha) /(1-\delta)$ is sufficiently small. Furthermore, this implies that our 
previous result on turbulence (Proposition 4) extends as well to the case where fixed costs are weakly increasing with market size.

What assumption on the reduced-form profit function gives rise to this sorting result? As should be clear from our discussion above, the key step consists in showing that the marginal type $c_{i j}$ would produce a larger output in the larger market $i$ than in market $j$. If competition is (endogenously) at least as intense in the larger market $i$ (case [ii] above), then this follows immediately from (COMP). Otherwise (case [i] above), we need an additional assumption on the reducedform profit function, namely that the equilibrium output of a firm is decreasing as more (or more efficient) firms enter, and price competition is more intense, namely, $q[c ; h(\mu), S]$ is decreasing in $h(\mu)$. In terms of the reduced-form profit function, this is equivalent to assuming that for $h\left(\mu^{\prime}\right)>h(\mu)$, the profit difference $\Pi[c ; h(\mu)]-\Pi\left[c ; h\left(\mu^{\prime}\right)\right]$ is decreasing in $c$. It can easily be verified that this property holds not only for the linear demand model, but also for the Dixit-Stiglitz CES (or constant elasticity of subsititution) model, and for the Cournot model (provided quantities are strategic substitutes).

Turning to the empirical application, for many small service industries, the rental price of office space is a major component of a firm's fixed cost (and the one that is most likely to vary across geographical markets). Furthermore, we would expect rental prices of office space to be higher in larger cities/municipalities than in smaller ones. Indeed, in Asplund and Nocke (2006), where we investigate firm turnover among hair salons in Sweden, we find a strong positive correlation between land values (as a proxy for rents) and market size (measured as the population living in the postal area). ${ }^{14}$

\subsection{Trade between Markets}

Thus far, we have assumed that an entrepreneur can sell her product only in the local market she chooses to locate production in. In this section, we extend the baseline model by allowing entrepreneurs to export their goods to other geographical markets (countries or regions) at a unit transport cost or tariff. We show that the central sorting result continues to hold. However, depending on the size of transport costs, no entrepreneur may decide to enter the smallest market(s). In fact, if transport costs are sufficiently small, then all entrepreneurs will enter the largest market.

14. Of course, in a cross-industry study, there is no reason to believe that fixed costs are positively correlated with industry size. However, one may envisage the following empirical strategy. First, following Sutton (1991), by using industry sales as a proxy for market size and engineering estimates (if available) as a proxy for fixed costs. Second, by splitting the sample into four (or more) subsamples, according to whether market size is large or small and whether fixed costs are large or small. Although our theory remains silent when comparing large markets with small fixed costs and small markets with high fixed costs, it allows us to make predictions on entrepreneurial efficiency and churning when comparing large markets with high fixed costs and small markets with low fixed costs. 
As in the baseline model, an entrepreneur will locate production in a single (geographical) market. However, she can now sell her product in all other markets but has to incur a unit transport cost or tariff $t$. Assuming that a type- $c$ entrepreneur produces at constant marginal cost $c$, the unit cost of selling in a "foreign" market is then equal to $c+t .{ }^{15}$ Because entrepreneurs can set different prices in the home and foreign markets, a type- $c$ entrepreneur sets the same price (or quantity) as a foreign type- $(c+t)$ entrepreneur in the foreign entrepreneur's home market. There are no additional fixed costs associated with exports. For simplicity, we assume that the fixed cost of production, $\varphi$, is the same in all markets, and that demand is linear (i.e., the reduced-form profit function is given by equation [1]). ${ }^{16}$

We need to distinguish between the distribution of entrepreneurial types producing in a given market, summarized by the (Borel) measure $\hat{\mu}_{i}$ on $[0,1]$, and the distribution of types selling in that market, summarized by measure $\mu_{i}$ on $[0,1+t]$. Because a foreign type- $(c+t)$ entrepreneur behaves like a home type- $c$ entrepreneur, the mass of entrepreneurs selling in market $i$ whose types fall into the interval $A$ is given by

$$
\mu_{i}(A)=\hat{\mu}_{i}(A)+\sum_{j \neq i} \hat{\mu}_{j}(A-t) .
$$

As in the baseline model without trade, price competition is more intense in larger markets.

LEMMA 1. The larger is the market, the more intense is price competition among firms selling in that market:

$$
h\left(\mu_{1}\right)>\cdots>h\left(\mu_{k}\right) \geq \cdots \geq h\left(\mu_{N}\right),
$$

where $k \in\{1, \ldots, N\}$ is the largest integer such that $\hat{\mu}_{k}([0,1])>0$ (i.e., $k$ is the smallest market in which a positive mass of entrepreneurs locate).

See the technical appendix (Nocke 2005) for a proof.

In contrast to the baseline model without trade, an entrepreneur will not necessarily locate her production in the market in which it can make the largest profit from domestic sales. Instead, she will prefer to locate production in market $i$ rather than in market $j$ if

$$
S_{i}\left\{\Pi\left[c ; h\left(\mu_{i}\right)\right]-\Pi\left[c+t ; h\left(\mu_{i}\right)\right]\right\}>S_{j}\left\{\Pi\left[c ; h\left(\mu_{j}\right)\right]-\Pi\left[c+t ; h\left(\mu_{j}\right)\right]\right\},
$$

15. It can be shown that the same results obtain with "iceberg-type" transport costs, where a type- $c$ firm's marginal cost of selling in a foreign market is $\tau c$ with $\tau>1$.

16. It is straightforward to embed this model in a general equilibrium model. For instance, we may assume that - apart from entrepreneurial ability - there is a single input, labor. In addition to the differentiated products, there is a homogeneous good, which is produced in all countries in a perfectly competitive industry, using a constant-returns-to-scale technology. The wage rate is thus determined in the homogeneous good industry, and is the same in all countries. 
that is, if the profit increase resulting from avoiding the transport cost for sales in market $i$ is larger than the corresponding profit increase for sales in market $j$. Nevertheless, the central sorting result carries over to our model with trade.

PROPOSITION 6. In the model with trade between markets, the equilibrium exhibits sorting of entrepreneurs by capabilities. In equilibrium, there exists a market $k \in\{1, \ldots, N\}$ and marginal types $0 \equiv \hat{c}_{0}<\hat{c}_{1}<\cdots<\hat{c}_{k}$ such that (almost) all entrepreneurs of type $c \in\left[\hat{c}_{i-1}, \hat{c}_{i}\right.$ ) enter market $i$, while (almost) all entrepreneurs of type $c \in\left[\hat{c}_{k}, 1\right]$ do not enter any market.

See the technical appendix (Nocke 2005) for the proof of this proposition.

Observe that consumers may enjoy a larger product variety in a smaller market, even if the mass of entrepreneurs locating in the smaller market is smaller. To see this, note that the more competitive is the market, the more talented entrepreneurs must be in order to make positive sales. Hence, entrepreneurs located in a large market (who are very efficient) will make positive export sales in smaller markets (provided transport costs are not too large); in contrast, an entrepreneur who is located in a small market may not be efficient enough to make export sales in a large market where competition is more intense.

Another empirical prediction of our model is that exporters are (on average) more efficient than non-exporters. This is for two reasons. First, consider firms located in the same market: In order to being able to profitably export to market $i$, a firm's marginal cost has to be less than $\bar{c}\left(\mu_{i}\right)-t$. Second, note that more efficient firms locate in larger markets and attempt to export to smaller and endogenously less competitive markets. For example, suppose there are only two markets, a large market 1 and a small market 2 . In equilibrium, $\bar{c}\left(\mu_{1}\right)<\bar{c}\left(\mu_{2}\right)$. To profitably export to market 1 , a firm's marginal cost has to be less than $\bar{c}\left(\mu_{1}\right)-t$, while the upper bound on marginal costs for exports to market 2 is $\bar{c}\left(\mu_{2}\right)-t>\bar{c}\left(\mu_{1}\right)-t$. Because the more efficient firms endogenously locate in market 1 , they are more likely to export. Indeed, there is strong empirical evidence supporting this prediction (see Bernard and Jensen 1999).

In contrast to our baseline model without trade, assuming that the fixed cost $\varphi$ is sufficiently small, and the mass $M$ of potential entrepreneurs sufficiently large no longer ensures that a positive mass of entrepreneurs locate in each market. Small markets may solely rely on "imports" because entrepreneurs may find it optimal to locate production in larger markets where domestic sales are larger, and then export to other markets. The extent to which this may happen depends on the magnitude of transport costs. If transport costs are small, then an entrepreneur either enters the largest market or does not enter any market. 
PROPOSITION 7. Suppose transport cost t is "sufficiently small". Then, in equilibrium, (almost) all entrepreneurs of type $c \in\left[0, \hat{c}_{1}\right)$ enter market 1 , while (almost) all entrepreneurs of type $\left[\hat{c}_{1}, 1\right]$ do not enter any market.

See the technical appendix (Nocke 2005) for the proof of this proposition.

In the limit as transport costs go to zero, the most capable entrepreneurs enter the largest market, less capable entrepreneurs do not enter any market, and no entrepreneur enters any market other than the largest. Intuitively, the existence of a transport cost implies that, by entering a larger rather than a smaller market, an entrepreneur is more efficient in the larger (and endogenously more competitive) market, and less efficient in the smaller (and less competitive) market. The marginal increase in profit from sales in market $i$ from having slightly lower marginal costs in that market is equal to an entrepreneur's output in market $i$. If transport costs are small, the intensity of price competition is approximately the same in all markets, and so the home market output for any type is greater in larger markets. Consequently, all entrepreneurs prefer to enter a larger rather than a smaller market when transport costs are sufficiently small. As transport costs become small, firms locate production in the market that allows them to minimize total transport costs, and this is the largest market.

Over the past twenty years, fears have been expressed by smaller countries that (symmetric) trade liberalization may lead to de-location of firms and even to de-industrialization (see Baldwin and Robert-Nicoud 2000). In our simple model, this fear seems to be well-grounded, even though it does not mean that trade liberalization has negative welfare implications.

Under what assumption on the reduced-form profit function do the predictions obtain? Proposition 6 requires two assumptions in addition to those of the baseline model, namely that for $h\left(\mu^{\prime}\right)>h(\mu)$, (i) the difference $\Pi[c ; h(\mu)]-\Pi\left[c ; h\left(\mu^{\prime}\right)\right]$ is decreasing in $c$, and (ii) the ratio

$$
\frac{\Pi\left[c ; h\left(\mu^{\prime}\right)\right]-\Pi\left[c+t ; h\left(\mu^{\prime}\right)\right]}{\Pi[c ; h(\mu)]-\Pi[c+t ; h(\mu)]}
$$

is decreasing in $c$. Assumption (i) is the same assumption we required in Section 5.1; it holds not only for the linear demand model, but also in the Cournot model when quantities are strategic substitutes (as is commonly assumed). Assumption (ii) holds in the linear demand model, and in the Cournot model provided demand is downward-sloping. To prove Proposition 7, only a technical regularity condition is required, namely that the partial derivatives of $\Pi[c ; h(\mu)]$ with respect to $c$ and $h$ are locally continuous in both arguments (for $c<\bar{c}[\mu])$. 


\section{Conclusion}

The aim of this paper has been to present a simple theory of entrepreneurial entry and exit, where (young) entrepreneurs decide which market to enter. We have obtained a striking sorting result: In equilibrium, the most talented entrepreneurs all choose to enter the largest market, less talented entrepreneurs enter the next largest market, and so on. The larger the market, the more efficient are thus its entrants. This result follows naturally from properties of standard models of imperfect competition. It may provide an alternative explanation for the empirical finding that factor productivity is greater in larger cities or regions. In fact, in a recent empirical study using French data, Combes, Duranton, and Gobillon (2003) show that a large fraction of the observed spatial wage disparities is due to sorting of more talented workers into larger towns. ${ }^{17}$ Reconsidering the relationship between market size and the number of firms, we have shown that the sorting effect may reinforce the price competition effect. In fact, the sorting effect may be so strong that the number of active firms (and hence product variety) is not necessarily larger in larger markets.

Our sorting result continues to hold when entrepreneurs can export their goods or services from one market (region, country) to another. In this case, however, no entrepreneur may decide to enter the smallest market(s). For sufficiently small transport costs, all active entrepreneurs locate in the largest market. This illustrates that a symmetric reduction in trade barriers may lead to a de-location of firms at the expense of small regions or countries.

In the dynamic extension of our model, we have shown that the churning rate of entrepreneurs is higher in larger markets (provided entrepreneurial efficiency levels do not change at too fast a rate), and so the life span of firms is shorter. Consequently, the age distribution of firms in larger markets is shifted towards younger firms. This is consistent with the empirical evidence on local service industries in Sweden, as shown in Asplund and Nocke (2000, 2006).

As discussed in the introduction, our theory abstracts from several issues in the economics of entrepreneurship, such as the role of risk and liquidity constraints. Moreover, we have assumed that each entrepreneur cannot enter more than one market. Our theory therefore only applies to those industries where the entrepreneurial span of control has strongly diminishing returns across different markets. ${ }^{18}$ Also, we have assumed that all entrepreneurs are completely

17. Our theory is concerned with the sorting of entrepreneurs rather than workers but can easily be extended to allow for sorting of workers (by introducing complementarities between the capabilities of entrepreneurs and those of [skilled] workers).

18. In the extreme case, where a firm could enter any number of markets (and, on the cost side, these entry decisions are completely independent from one another), our results on the relationship between efficiency and market size would be reversed: the most efficient firms enter all markets, while less efficient firms only enter the larger markets. 
mobile and may decide to enter any one market. Although this may be an extreme assumption, it allows us to analyze a benchmark case without having to make assumptions on the initial distribution of potential entrants over geographical locations. In any event, even if a fraction of entrepreneurs are not mobile, the intuition for the sorting result should still hold for all those entrepreneurs who are mobile, and thus imply that entrepreneurial firms in larger markets are more efficient.

\section{Appendix}

Proof of Proposition 1. In the main text, we have shown that if an entrepreneur of type $c_{i j}$ is indifferent between entering market $i$ and a smaller market $j>i$, then all more efficient types strictly prefer to enter the larger market $i$, while all less efficient types strictly prefer to enter market $j$. Because we assume that entry and fixed costs are sufficiently small, and the mass of potential entrepreneurs $M$ sufficiently large, a positive mass of entrepreneurs must enter each market, and a positive mass of entrepreneurs does not enter any market. Hence, in equilibrium, there exist marginal types $\left\{c_{i}\right\}_{i=0}^{N}$ such that $c_{i}<c_{i+1}$,

$$
\begin{aligned}
c_{0} & \equiv 0, \\
S_{i} \Pi\left[c_{i} ; h\left(\mu_{i}\right)\right] & =S_{i+1}\left[c_{i} ; h\left(\mu_{i+1}\right)\right], \quad i=1, \ldots, N-1, \\
S_{N} \Pi\left[c_{N} ; h\left(\mu_{N}\right)\right] & =\varphi .
\end{aligned}
$$

As is well known, there always exists a pure-strategy Nash equilibrium in games with a continuum of atomless players and a countable and finite set of actions; see, for instance, theorems 1 and 2 in Mas-Colell (1984), or corollary 1 in Khan and Sun (1995). (Furthermore, if the distribution of entrepreneurial types has no mass points, as we assume, then there exists a "symmetric" pure-strategy equilibrium in which all entrepreneurs of the same type $c$ choose the same action, i.e., enter the same market.) We now want to prove uniqueness of equilibrium. For this, suppose there exist marginal types $\left\{\tilde{c}_{i}\right\}_{i=0}^{N} \neq\left\{c_{i}\right\}_{i=0}^{N}$ satisfying $\left(\mathrm{E}_{0}\right)$ to $\left(\mathrm{E}_{N}\right)$. Assume, for instance, that $\tilde{c}_{N}<c_{N}$. For $\left(\mathrm{E}_{N}\right)$ to hold, we thus have $h\left(\tilde{\mu}_{N}\right)>h\left(\mu_{N}\right)$. The last observation in turn implies that $\tilde{c}_{N-1}<c_{N-1}$. To see this, suppose instead that $\tilde{c}_{N-1} \geq c_{N-1}$; however, from $\tilde{c}_{N}<c_{N}$ and (DOM), it would then follow that $h\left(\tilde{\mu}_{N}\right) \leq h\left(\mu_{N}\right)$, contradicting our finding that $h\left(\tilde{\mu}_{N}\right)>h\left(\mu_{N}\right)$. Observe now that, for given measures $\mu_{i}$ and $\mu_{i+1}$, the marginal type $c_{i}$ is uniquely defined by $\left(\mathrm{E}_{i}\right)$, where uniqueness follows from (COMP); furthermore, $c_{i}$ is decreasing in $h\left(\mu_{i}\right)$ and increasing in $h\left(\mu_{i+1}\right)$. Hence, $\tilde{c}_{N-1}<c_{N-1}$ and $h\left(\tilde{\mu}_{N}\right)>h\left(\mu_{N}\right)$ imply that $h\left(\tilde{\mu}_{N-1}\right)>h\left(\mu_{N-1}\right)$. Following the same steps of argument, we obtain that $\tilde{c}_{i}<c_{i}$ and $h\left(\tilde{\mu}_{i}\right)>h\left(\mu_{i}\right)$ for all $i \in\{1, \ldots, N\}$. However, $\tilde{c}_{1}<c_{1}$ 
and $\tilde{c}_{0}=c_{0}=0$ imply that $h\left(\tilde{\mu}_{1}\right)<h\left(\mu_{1}\right)$, contradicting $h\left(\tilde{\mu}_{1}\right)>h\left(\mu_{1}\right)$. Hence, we cannot have $\tilde{c}_{N}<c_{N}$. A similar reasoning yields that we cannot have $\tilde{c}_{N}>c_{N}$. We therefore conclude that $\tilde{c}_{N}=c_{N}$. Suppose now that $\tilde{c}_{N}=c_{N}$ and $\tilde{c}_{N-1}<c_{N-1}$. It then follows that $h\left(\tilde{\mu}_{N-1}\right)>h\left(\mu_{N-1}\right)$. As before, it is straightforward to show that this leads to a contradiction. Applying these arguments to all $i \in\{1, \ldots, N\}$, we find that $\tilde{c}_{i}=c_{i}$ for all $i \in\{0,1, \ldots, N\}$, proving uniqueness of equilibrium.

Proof of Proposition 2. Note that (COMP) holds if and only if

$$
\frac{\Pi_{1}\left[c ; h\left(\mu^{\prime}\right)\right]}{\Pi\left[c ; h\left(\mu^{\prime}\right)\right]}<\frac{\Pi_{1}[c ; h(\mu)]}{\Pi[c ; h(\mu)]} \quad \forall c \in\left[0, \bar{c}\left(\mu^{\prime}\right)\right], h\left(\mu^{\prime}\right)>h(\mu) .
$$

Applying the envelope theorem, this inequality yields $p\left[c ; h\left(\mu^{\prime}\right)\right]<p[c ; h(\mu)]$.

Proof of Proposition 3. The proof is similar to that of Proposition 1. The first step consists in showing that, in equilibrium, the distribution of active entrepreneurs is larger (in the sense of representing more intense competition) in larger markets: $h\left(\mu_{i}\right)>h\left(\mu_{j}\right)$ for any markets $i$ and $j>i$. The proof of this assertion proceeds as before. The remaining steps are slightly more involved. Because we assume that each market is sufficiently large relative to entry and fixed costs (so that each market is non-empty in equilibrium) and because the conditional value is continuous in $c$, for any two markets $i$ and $j>i$, there exists some type, say $c_{i j}$, who is indifferent between entering markets $i$ and $j: \bar{V}\left[c_{i j} ; h\left(\mu_{i}\right), S_{i}\right]=$ $\bar{V}\left[c_{i j} ; h\left(\mu_{j}\right), S_{j}\right]$. Similarly, there exists a unique type, say $\hat{c}_{i j}$, who would make the same (current) profit in both markets: $S_{i} \Pi\left[\hat{c}_{i j} ; h\left(\mu_{i}\right)\right]=S_{j} \Pi\left[\hat{c}_{i j} ; h\left(\mu_{j}\right)\right]$. Assumption (COMP) ensures that the profit ratio $\Pi\left(c ; h\left(\mu_{i}\right)\right) / \Pi\left(c ; h\left(\mu_{j}\right)\right)$ is decreasing in $c$ on $\left[0, \bar{c}\left(\mu_{i}\right)\right]$. If $c_{i j} \leq \hat{c}_{i j}$, then it is straightforward to see that the ratio of conditional values, $\bar{V}\left[c ; h\left(\mu_{i}\right), S_{i}\right] / \bar{V}\left[c ; h\left(\mu_{j}\right), S_{j}\right]$, is decreasing in $c$ at $c=c_{i j}$; this holds independently of the level of $\delta(1-\alpha) /(1-\delta)$. In this case, any type more efficient than $c_{i j}$ strictly prefers to enter market $i$, whereas all less efficient types prefer to enter the smaller market $j$. Now, if $c_{i j}$ is (much) larger than $\hat{c}_{i j}$, then the ratio of conditional values may not be monotonically decreasing in $c$. By assuming that $\delta(1-\alpha) /(1-\delta)$ is small, we ensure that $c_{i j}$ is close to $\hat{c}_{i j}$, and hence that $\bar{V}\left[c ; h\left(\mu_{i}\right), S_{i}\right] / \bar{V}\left[c ; h\left(\mu_{j}\right), S_{j}\right]$ is decreasing in $c$ at $c=c_{i j}$. The asserted sorting result follows then immediately. Uniqueness of equilibrium can be shown in a way similar to the proof of Proposition 1. Note that the assumption that $\delta(1-\alpha) /(1-\delta)$ is small implies that the marginal incumbent $c^{*}(\mu, S)$ (who is just indifferent between exiting and staying in the market) makes a positive gross profit, $S \Pi\left[c^{*}(\mu, S) ; h(\mu)\right]>0$, and hence $c^{*}(\mu, S)<\bar{c}(\mu)$ (as we posited before). 


\section{References}

Asplund, Marcus, and Volker Nocke (2000). "Imperfect Competition, Market Size and Firm Turnover." CEPR Discussion Paper No. 2625.

Asplund, Marcus, and Volker Nocke (2006). "Firm Turnover in Imperfectly Competitive Markets." Review of Economic Studies, 73, 295-327.

Baldwin, Robert E., and Frederic Robert-Nicoud (2000). "Free Trade Agreements without Delocation." Canadian Journal of Economics, 33, 766-786.

Bartelsman, Eric J., and Mark Doms (2000). "Understanding Productivity: Lessons from Longitudinal Microdata." Journal of Economic Literature, 38, 569-595.

Bernard, Andrew B., and J. Bradford Jensen (1999). "Exceptional Exporter Performance: Cause, Effect, or Both?" Journal of International Economics, 47, 1-25.

Bowley, Arthur L. (1924). The Mathematical Groundwork of Economics. Clarendon Press.

Bresnahan, Timothy F., and Peter C. Reiss (1991). "Entry and Competition in Concentrated Markets.” Journal of Political Economy, 99, 977-1009.

Cabral, Luis M. B. (1997). "Competitive Industry Dynamics: A Selective Survey of Facts and Theories." Working paper, London Business School.

Caves, Richard E. (1998). "Industrial Organization and New Findings on the Turnover and Mobility of Firms." Journal of Economic Literature, 36, 1947-1982.

Combes, Pierre-Philippe, Gilles Duranton, and Laurent Gobillon (2003). "Spatial Wage Disparities: Sorting Matters!" Working paper, CERAS, London School of Economics, and University College London.

Davis, Donald R., and David E. Weinstein (2001). "Market Size, Linkages, and Productivity: A Study of Japanese Regions." NBER Working Paper No. 8518.

Davis, Steven J., and John C. Haltiwanger (1999). "Gross Job Flows.” In Handbook of Labor Economics, vol. 3B, edited by Orley Ashenfelter and David Card. North Holland.

Ericson, Richard, and Ariel Pakes (1995). "Markov-Perfect Industry Dynamics: A Framework for Empirical Work." Review of Economic Studies, 62, 53-82.

Evans, David S., and Boyan Jovanovic (1989). "An Estimated Model of Entrepreneurial Choice under Liquidity Constraints." Journal of Political Economy, 97, 808-827.

Henderson, J., Vernon (1986). "Efficiency of Resource Usage and City Size." Journal of Urban Economics, 19, 47-70.

Holmes, Thomas J., and James A. Schmitz (1990). "A Theory of Entrepreneurship and its Application to the Study of Business Transfers." Journal of Political Economy, 98, 265-294.

Hopenhayn, Hugo A. (1992). "Entry, Exit, and Firm Dynamics in Long Run Equilibrium." Econometrica, 60, 1127-1150.

Jovanovic, Boyan (1982). "Selection and the Evolution of Industry." Econometrica, 50, 649-670.

Khan, M. Ali, and Yeneng Sun (1995). "Extremal Structures and Symmetric Equilibria with Countable Actions." Journal of Mathematical Economics, 24, 239-248.

Kihlstrom, Richard E., and Jean-Jacques Laffont (1979). "A General Equilibrium Theory of Firm Formation Based on Risk Aversion.” Journal of Political Economy, 87, 719-748.

Lambson, Val. E. (1991). "Industry Evolution with Sunk Costs and Uncertain Market Conditions." International Journal of Industrial Organization, 9, 171-196.

Lucas, Robert E. (1978). "On the Size Distribution of Business Firms." Bell Journal of Economics, 9, 508-523.

Marshall, Alfred (1890). Principles of Economics. Macmillan.

Mas-Colell, Andreu (1984). "On a Theorem by Schmeidler." Journal of Mathematical Economics, 13, 201-206.

Nocke, Volker (2003). "A Gap for Me: Entrepreneurs and Entry.” PIER Working Paper No. 03-019. 
Nocke, Volker (2005). “A Gap for Me: Entrepreneurs and Entry.” Technical Appendix, available at http://www.econ.upenn.edu/ nocke/gap-technicalappendix.pdf.

Rosen, Sherwin (1981). "The Economics of Superstars." American Economic Review, 81, 845-858.

Rosen, Sherwin (1982). "Authority, Control, and the Distribution of Earnings.” Bell Journal of Economics, 13, 311-323.

Roth, Alwin E., and Marilda A. Oliveira Sotomayor (1990). Two-Sided Matching. A Study in Game-Theoretic Modeling and Analysis. Econometric Society Monograph No. 18, Cambridge University Press.

Sutton, John (1991). Sunk Costs and Market Structure. MIT Press.

Sutton, John (1997). "Gibrat's Legacy.” Journal of Economic Literature, 35, 40-59.

Sveikauskas, Leo A. (1975). "The Productivity of Cities." Quarterly Journal of Economics, 89, 393-413.

Syverson, Chad (2004). "Market Structure and Productivity: A Concrete Example.” Journal of Political Economy, 112, 1181-1222.

Vives, Xavier (1999). Oligopoly Pricing. MIT Press.

Vives, Xavier (2005). "Innovation and Competitive Pressure." Working paper, ICREA-UPF and INSEAD. 
Copyright of Journal of the European Economic Association is the property of MIT Press and its content may not be copied or emailed to multiple sites or posted to a listserv without the copyright holder's express written permission. However, users may print, download, or email articles for individual use. 